J. Lake Sci. (湖泊科学) , 2014, 26(5): 707-712

http://www. jlakes. org. E-mail : jlakes@niglas.ac.cn

(c) 2014 by Journal of Lake Sciences

\title{
滆湖水体光学性质初步研究”
}

\author{
何尚卫 ${ }^{1,2}$,李 勇 $^{1,2}$,赵海光 ${ }^{3}$, 潘继征 ${ }^{4 * *}$ \\ (1: 苏州科技学院环境科学与工程学院,苏州 215011) \\ (2: 江苏省环境科学与工程重点实验室,苏州 215011) \\ (3: 云南省环境科学研究院,昆明 650034) \\ (4: 中国科学院南京地理与湖泊研究所湖泊与环境国家重点实验室, 南京 210008)
}

摘 要: 基于 2009 年 7 月至 2010 年 6 月滆湖全湖 15 个采样点的水体光学参数及相关水质理化因子数据, 分析滆湖水体 周年光合有效辐射 (PAR) 衰减特性, 以期为滆湖沉水植物生态修复提供相关水体光学资料. 结果表明,滆湖水体 PAR 衰 减系数 $\left(K_{\mathrm{d}}\right)$ 周年变化范围为 $1.32 \sim 17.42 \mathrm{~m}^{-1}$. 秋季 $K_{\mathrm{d}}$ 相对最小, 平均值为 $2.35 \mathrm{~m}^{-1}$, 变化范围为 $1.32 \sim 3.70 \mathrm{~m}^{-1}$; 夏 季 $K_{\mathrm{d}}$ 相对最大, 平均值为 $6.23 \mathrm{~m}^{-1}$, 变化范围为 $3.68 \sim 17.42 \mathrm{~m}^{-1}$. 春、秋、冬季, 滆湖水体真光层平均深度均满足沉水植 物的生长需求, 而在夏季滆湖水体真光层平均深度仅为 $0.84 \mathrm{~m}$, 小于全湖平均水深 $(1.20 \mathrm{~m})$, 因此夏季 PAR 是限制沉水 植物恢复的因子之一. 滆湖水体 $K_{\mathrm{d}}$ 与透明度 $(\mathrm{SD})$ 在秋、冬季的关系为 $K_{\mathrm{d}}=2.089+0.705 / \mathrm{SD}$. 叶绿素 a 浓度和悬浮物浓 度是影响滆湖水体 $K_{\mathrm{d}}$ 的重要因子之一.

关键词: 滆湖;PAR;沉水植物;真光层深度

\section{Preliminary study on the optical properties of Lake Gehu}

HE Shangwei ${ }^{1,2}$, LI Yong ${ }^{1,2}$, ZHAO Haiguang $^{3} \&$ PAN Jizheng ${ }^{4}$

(1: School of Environmental Science and Engineering, Suzhou University of Science and Technology, Suzhou 215011, P. R. China)

(2: Key Laboratory of Environmental Science and Engineering of Jiangsu Province, Suzhou University of Science and Technology, Suzhou 215011, P. R. China)

(3: Yunnan Institute of Environmental Science, Kunming 650034, P. R. China)

(4: State Key Laboratory of Lake Science and Environment, Nanjing Institute of Geography and Limnology, Chinese Academy of Sciences, Nanjing 210008, P. R. China)

Abstract: Seasonal variations of the optical parameters and physicochemical properties of lake water at 15 sampling sites were investigated, from July 2009 to June 2010, to provide the basic lake optical properties data for submerged aquatic vegetations restoration of a shallow lake-Lake Gehu. The annual variation of the attenuation coefficient of photosynthetically active radiation $\left(K_{\mathrm{d}}\right)$ was $1.32-17.42 \mathrm{~m}^{-1}$. The minimum and maximum values of $K_{\mathrm{d}}$ were observed in autumn $\left(1.32-3.70 \mathrm{~m}^{-1}\right)$ and summer $\left(3.68-17.42 \mathrm{~m}^{-1}\right.$ ), with a medium value of $2.35 \mathrm{~m}^{-1}$ and $6.23 \mathrm{~m}^{-1}$, respectively. The average euphotic zone depth in spring, fall and winter can satisfy the demand of submerged aquatic vegetation. However, the average euphotic zone depth was only $0.84 \mathrm{~m}$ in summer, which was less than the average water $\operatorname{depth}(1.20 \mathrm{~m})$ of Lake Gehu and implied that the photosynthetically active radiation was one of the inhibiting factors to restore the submerged aquatic vegetations in summer. The $K_{\mathrm{d}}$ and secchi disk depth (SD) in fall and winter had the relationship of $K_{\mathrm{d}}=2.089+0.705 / \mathrm{SD}$. Chlorophyll-a and suspended solid were the factors influencing the $K_{\mathrm{d}}$ value in Lake Gehu.

Keywords: Lake Gehu; photosynthetically active radiation (PAR); submerged aquatic vegetation; euphotic zone depth

* 国家水体污染控制与治理科技重大专项项目 (2012ZX07101-007-01) 资助. 2013-08-23 收稿; 2013-12-18 收修 改稿. 何尚卫(1989 ), 男,硕士研究生;E-mail:763713334@ qq. com.

** 通信作者;E-mail: jzhpan@ niglas. ac. cn. 
光合有效辐射 (PAR) 在湖泊生态系统中具有重要的地位 ${ }^{[1-3]}$, 是沉水植物生长的必须环境因子及主要 限制因子 ${ }^{[3-5]}$. 纯水、浮游植物、悬浮颗粒物、有色可溶性有机物 ( CDOM) 是影响浅水湖泊水体 PAR 的主要因 素 ${ }^{[6-8]}$. 不同类型的湖泊或湖区及在不同季节时, 由悬浮颗粒物、浮游植物、CDOM 而造成的 PAR 衰减不同. 如崇明岛中心湖水体因悬浮物和有机物而导致 PAR 四季衰减呈现显著差异 ${ }^{[6]}$, 而在太湖梅樑湾夏、秋季由 于藻类的大量生长, 导致 PAR 衰减显著大于冬季 ${ }^{[7]}$; 在西湖冬、春季水体光学特性的主要影响因素是浮游植 物和悬浮物 ${ }^{[8]}$. 湖泊水体的 PAR 强烈衰减, 可能会造成沉水植物生长所需要的光难以到达湖底 ${ }^{[9]}$, 进而影 响沉水植物的衰退. 因此, 欲对某一特定的湖泊水体进行沉水植物修复, 有必要对水体 PAR 及关键影响因子 进行相关基础研究. 否则, 在忽视水体 PAR 分布的情况下, 盲目进行沉水植物的修复很容易失败.

滆湖 ( $31^{\circ} 29^{\prime} \sim 31^{\circ} 42^{\prime} \mathrm{N}, 119^{\circ} 44^{\prime} \sim 119^{\circ} 53^{\prime} \mathrm{E}$ ) 位于常州西南, 面积 $146 \mathrm{~km}^{2}$, 原平均水深 $1.2 \mathrm{~m}^{[10]}$, 在 $1990 \mathrm{~s}$ 水生植物非常丰富, 而后逐渐演化成藻型湖泊, 仅在部分湖区还有沉水植物存活 ${ }^{[11]}$. 为重建滆湖水体 中的沉水植物, 于 $2008-2011$ 年对滆湖北部湖区进行综合整治, 以期能够为沉水植物的生长繁殖提供基础 条件. 对于影响滆湖水体中沉水植物生长的重要营养元素氮、磷, 已有许多学者进行了相关研究 ${ }^{[12-14]}$, 但影 响滆湖水体中沉水植物能否修复的重要因子一一水体 PAR 的衰减及其相关因子尚没有具体研究. 本文对 2009 年 7 月至 2010 年 6 月滆湖全湖的 PAR 特性进行研究, 旨在初步了解滆湖水体在综合整治时的光学性 状, 以期为以后评价综合整治效果及为优化滆湖生态修复措施提供基础资料.

\section{1 材料与方法}

\section{1 采样点与采样时间}

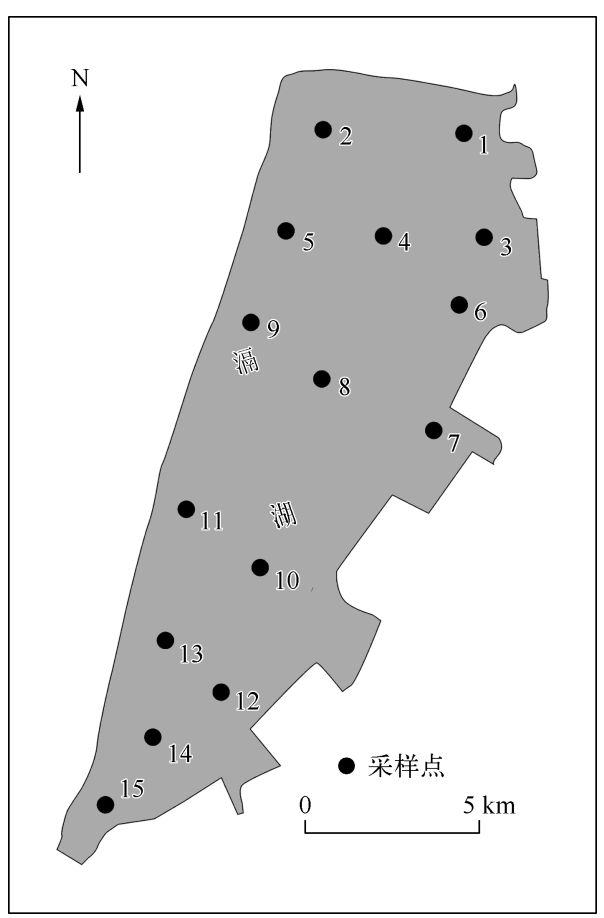

图 1 滆湖采样点位置

Fig. 1 Distribution of sampling sites in Lake Gehu

根据滆湖湖区的分布和周围环境状况, 设置了 15 个 采样点(图 1). 于 2009 年 7 月至 2010 年 6 月, 对滆湖水 体光学参数及相关水质理化因子进行测定, 其中 2009 年 10 月及 2010 年 4 月的光合有效辐射 (PAR) 未进行测定, 9 月仅对 $1^{\#} \sim 7^{\#}$ 采样点进行 PAR 测定. 2009 年 9 月至 2010 年 5 月测定水体透明度 (SD), 2010 年 5、6 月仅对采 样点 $4^{\#} 、 6^{\#} 、 10^{\#} 、 11^{\#}$ 的水质理化因子进行测定.

\section{2 采样与测定方法}

PAR 采用 XR-620 多参数水质剖面仪 ( RBR Ltd, Canada) 进行现场测定. 透明度用 $30 \mathrm{~cm}$ 的赛氏盘进行现 场测定. 用聚乙烯瓶采集各样点表层 $0.5 \mathrm{~m}$ 处水样, 快速 带回实验室进行分析. 叶绿素 a (Chl. a) 浓度采用 $90 \%$ 丙 酮浸提分光光度法进行测定 (2009 年 7 月至 2010 年 5 月). 悬浮物 (SS) 浓度采用称重法测定 (仅 2009 年 7 月). 总氮 (TN) 和总磷 (TP) 浓度分别采用碱性过硫酸钾消解 紫外分光光度法和钿酸铵分光光度法进行测定 ${ }^{[15]}$.

\section{3 衰减系数、真光层深度的计算及数据处理}

在光学性质均一的水体中, PAR 衰减符合以下 规律 ${ }^{[6-8]}$ :

$$
K_{\mathrm{d}}=-\frac{1}{Z} \ln \frac{E(Z)}{E(0)}
$$

式中, $K_{\mathrm{d}}$ 为漫射衰减系数, $Z$ 为从湖面到测量处的深度, $E$ $(Z) 、 E(0)$ 分别为深度为 $Z 、 0 \mathrm{~m}$ 处的 PAR 强度, $K_{\mathrm{d}}$ 值通 过对不同深度水下 PAR 强度进行回归得到 $\left(R^{2} \geqslant 0.90\right.$, 深度数 $\left.N \geqslant 8\right)$.

真光层深度 $\left(Z_{\mathrm{eu}}\right)$ 一般指水体表面辐照度为 $1 \%$ 处的深度, 计算公式为 ${ }^{[16]}$ : 


$$
Z_{\text {eu }}=\ln 100 / K_{\mathrm{d}}=4.605 / K_{\mathrm{d}}
$$

$\mathrm{SD}$ 与 $K_{\mathrm{d}}$ 之间通常存在反比的经验关系 ${ }^{[16-17]}$ :

$$
K_{\mathrm{d}}=a+b / \mathrm{SD}
$$

各参数平均值、线性回归均采用 Excel 2003 和 SPSS 16.0 进行统计分析; 分布图采用 Surfer 8.0 软件 绘制.

\section{2 结果与讨论}

\section{1 滆湖水质指标}

2009 年 7 月至 2010 年 6 月, 滆湖 TN、TP 浓度年平均值分别为 $3.85 、 0.22 \mathrm{mg} / \mathrm{L}$, 滆湖全湖水体基本处于 劣 $\mathrm{V}$ 类, 总体上已经处于中度富营养化后期 ${ }^{[18]}$. 湖泊水体中 TN $\mathrm{TP}$ 是一个重要的指标 ${ }^{[19-20]}$, 可以指示湖泊 水体中浮游植物的生长是受哪种营养元素的限制. 滆湖在 2009 年 7 月至 2010 年 6 月全湖每月 TN:TP 分别 为 $7.30 、 11.84 、 7.62 、 12.71 、 29.27 、 22.52 、 27.62 、 28.64 、 52.22 、 27.79 、 16.88 、 7.59$, 均大于 7 , 说明滆湖水体中的 $\mathrm{TP}$ 是浮游植物生长的限制因子 ${ }^{[16]} .2009$ 年 7-10 月及 2010 年 5-6 月 $\mathrm{TN}: \operatorname{TP}(7.30 \sim 12.71)$ 与 11 月至 4 月 $\mathrm{TN}: \mathrm{TP}(22.52 \sim 52.22)$ 呈现出明显的差异. 其中 2009 年 $7 、 9$ 月及 2010 年 6 月 TN:TP 均小于 10 , 说明在夏季 及初秋时节, 滆湖水体存在刺激浮游植物固氮作用的可能 ${ }^{[20]}$, 即在此期间存在着大量有固氮作用的藻类.

对滆湖全湖 2009 年至 2010 年 10 个月份的 Chl. a 浓度平均值和 TN:TP 平均值之间的关系进行拟合, 发 现滆湖水体中藻类含量与水体水质具有显著的负相关性 (公式 (4)). 夏季藻类的大量生长使水体 TN: TP 降 低 ${ }^{[21]}$, 进而可以诱导固氮藻类的生长繁殖.

$$
\text { Chl. a }=-42.651 \ln (\mathrm{TN}: \mathrm{TP})+174.728\left(R^{2}=0.852, N=10, P<0.001\right)
$$

\section{2 滆湖水体 $K_{\mathrm{d}}$ 的时空变化}

滆湖全湖水体 $K_{\mathrm{d}}$ 分布具有明显的时空变化. 将滆湖 2009 年 11 月和 2010 年 $1 、 3 、 6$ 月的全湖 $K_{\mathrm{d}}$ 作为 4 个 典型季节的分布 (图 2), 结果表明滆湖全湖周年 $K_{\mathrm{d}}$ 变化范围较大, 最小值为 $1.32 \mathrm{~m}^{-1}$, 最大值达 $17.42 \mathrm{~m}^{-1}$. 秋季全湖 $K_{\mathrm{d}}$ 变化范围为 $1.32 \sim 3.70 \mathrm{~m}^{-1}$, 平均值为 $2.35 \mathrm{~m}^{-1}$; 冬季全湖 $K_{\mathrm{d}}$ 变化范围为 $2.46 \sim 4.93 \mathrm{~m}^{-1}$, 平 均值为 $3.43 \mathrm{~m}^{-1}$; 春季全湖 $K_{\mathrm{d}}$ 变化范围为 $2.53 \sim 4.62 \mathrm{~m}^{-1}$, 平均值为 $3.71 \mathrm{~m}^{-1}$; 夏季全湖 $K_{\mathrm{d}}$ 变化范围为 $3.68 \sim 17.42 \mathrm{~m}^{-1}$, 平均值为 $6.23 \mathrm{~m}^{-1}$. 夏季滆湖水下光场是 4 个季节中最差的, 其中 6 月 $9^{\#}$ 采样点的 $K_{\mathrm{d}}$ 全 湖最大,这可能与其处于人湖口有关. 此外,南部湖区的周年 $K_{\mathrm{d}}$ 波动程度较北部湖区小.

全湖真光层深度变化范围为 $0.26 \sim 3.48 \mathrm{~m}$. 秋季全湖真光层深度变化范围为 $1.14 \sim 3.48 \mathrm{~m}$, 平均达 $2.24 \mathrm{~m}$; 冬季全湖真光层深度变化范围为 $0.93 \sim 1.87 \mathrm{~m}$, 平均达 $1.39 \mathrm{~m}$; 春季全湖真光层深度变化范围为 $1.00 \sim 1.82 \mathrm{~m}$, 平均达 $1.27 \mathrm{~m}$; 而夏季全湖真光层深度变化范围为 $0.26 \sim 1.25 \mathrm{~m}$, 平均仅为 $0.84 \mathrm{~m}$, 除采样 点 $9^{\#}$ 以外,其他采样点的真光层深度变化范围为 $0.60 \sim 1.25 \mathrm{~m}$. 在不考虑水位变化的情况下,春、秋、冬季全 湖水下光场情况基本可以满足沉水植物的重建,不会成为沉水植物群落生长和重建的限制因子;而在夏季 6 月份全湖大部分湖区真光层深度达不到全湖的平均深度, 且夏季水深通常较其他季节高,因此夏季滆湖水 体中光是沉水植物生长的限制因子之一.

湖泊水体中在 $K_{\mathrm{d}}$ 值较大 (低真光层深度) 的区域, 很少发现沉水植物 ${ }^{[22]} \cdot K_{\mathrm{d}}$ 和沉水植物之间处于一种不 断互相反馈的关系. 一方面, $K_{\mathrm{d}}$ 影响沉水植物的生存, $K_{\mathrm{d}}$ 增大将会使沉水植物生长所需要的光很难到达湖 底 ${ }^{[9]}$, 影响沉水植物的光合作用, 进而引起沉水植物的衰退. 另一方面, 沉水植物可以固定底泥, 抑制内源营 养盐的释放 ${ }^{[23]}$, 同时还可以释放化感物质抑制藻类的大量繁殖 ${ }^{[24]}$, 减少藻类对光的吸收和分散作用, 从而 提高水体的透明度并减少光衰减,使湖泊水体趋向于清水状态转变, 更有利于沉水植物的生长.

在 2009 年 5 月进行全湖水生植物现状调查时, 发现 $1^{\#}$ 采样点有沉水植物蕰草、金鱼藻存活, $13^{\#}$ 及 $14^{\#}$ 采 样点有沉水植物苦草, $15^{\#}$ 采样点有菱角、艾草和水鳖. 10 月全湖水生植物调查发现, $3^{\#}$ 采样点附近有成片的 金鱼藻和蕰草分布, $7^{\#}$ 采样点有马来眼子菜点状分布, $12^{\#}$ 采样点有点状的苦草、马来眼子菜及金鱼藻分布, $13^{\#}$ 采样点有苦草分布. 

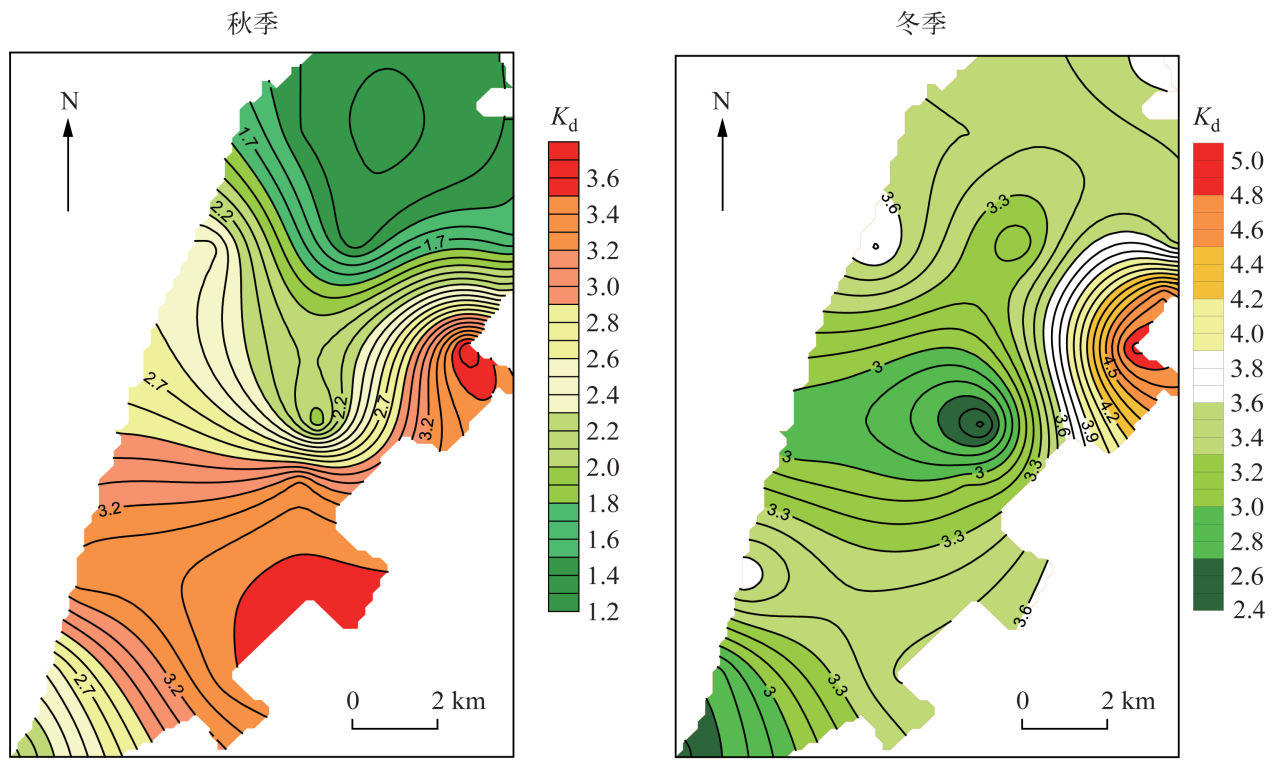

春季

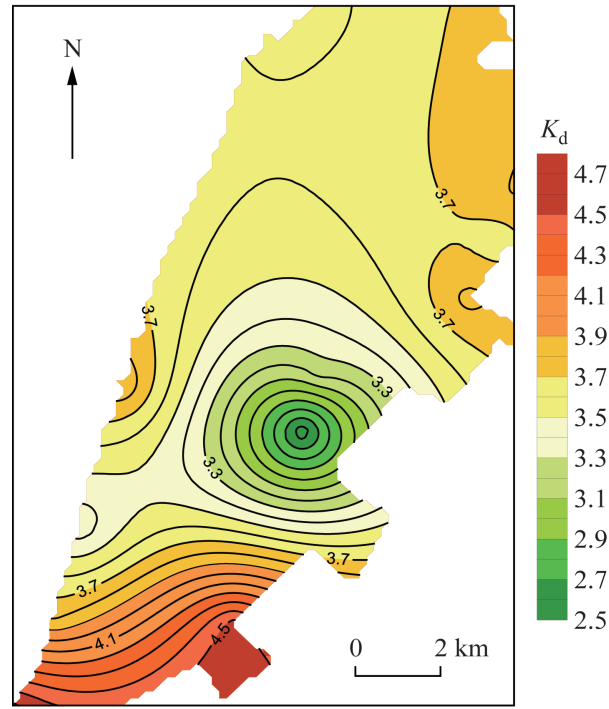

夏季

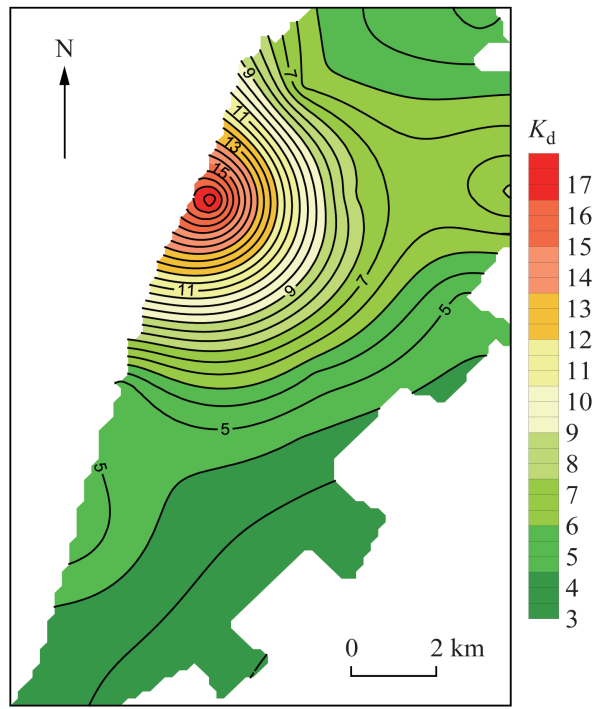

图 2 滆湖不同季节 $K_{\mathrm{d}}$ 分布

Fig. 2 Seasonal distribution of $K_{\mathrm{d}}$ in Lake Gehu

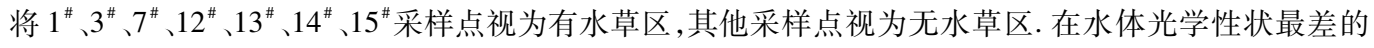
夏季 6 月, 有水草区的 $K_{\mathrm{d}}$ 值分别为 $4.89 、 7.64 、 4.83 、 3.68 、 5.50 、 4.36 、 4.40 \mathrm{~m}^{-1}$, 真光层深度变化范围为 $0.60 \sim 1.25 \mathrm{~m} .2009$ 年 10 月, 在 $3^{\#}$ 采样点及其附近发现有大量沉水植物菹草生长, 但 2010 年夏季 6 月该采 样点的 $K_{\mathrm{d}}$ 值却是所有水草区中最大的, 真光层深度仅 $0.60 \mathrm{~m}$, 这与菹草在夏季大量死亡有关. 菹草的大量死 亡增加了底泥再悬浮的能力, 并释放出大量的氮、磷营养元素至水体, 促进藻类的生长繁殖, 进而造成较差 的水下光场. 在夏季, 全湖无水草区的真光层深度变化范围为 $0.26 \sim 1.01 \mathrm{~m}$, 各采样点的真光层深度均小于 水深. 无水草区的采样点真光层深度明显小于有沉水植物生长的采样点. 


\section{3 滆湖水体 PAR 衰减特性分析}

$K_{\mathrm{d}}$ 和 $\mathrm{SD}$ 是水体的 2 个重要光学参数. 透明度盘可以用来测量单个水生态系统连续几年的 $\mathrm{SD}^{[16]}$, 其操 作简便,但因观测者不同, 读取的数值也有所不同. $K_{\mathrm{d}}$ 的测量能够精确地反映出水下光场情况, 但其常常受 到风速等天气情况的影响 ${ }^{[25]}$. 这 2 种测量技术都有其局限性 ${ }^{[16]}$, 因此常建立两者之间的经验关系式,对滆 湖水体 2009 年 11 月至 2010 年 1 月 $K_{\mathrm{d}}$ 与 $\mathrm{SD}$ 的关系进行拟合后得到:

$$
K_{\mathrm{d}}=2.089+0.705 / \mathrm{SD}\left(R^{2}=0.302, N=45, P<0.001\right)
$$

可以看出, 滆湖 2009-2010 年秋、冬季全湖 $K_{\mathrm{d}}$ 与 SD 之间有一定的相关性, 经验系数为 0.705 , 在 $0.5 \sim$ 3.8 范围内 ${ }^{[16]}$, 表明滆湖属于浑浊型的湖泊. 与太湖 $K_{\mathrm{d}}$ 与 $\mathrm{SD}$ 之间的经验系数 (1.369 $)^{[26]}$ 相比差异较大. 这 可能与太湖东半部分仍有大量沉水植物生长有关, 而滆湖全湖仅部分湖区有少量沉水植物; 抑或是因为太 湖经验系数计算时舍弃部分数据且经验系数为几周年的值,而滆湖 $K_{\mathrm{d}}$ 与 $\mathrm{SD}$ 之间的经验系数是 $2009-2010$ 年秋、冬季连续 3 个月份 (11月至 1 月) 的值.

由于夏季滆湖水体 $K_{\mathrm{d}}$ 分布同其他季节明显不同,其最大可达 $17.42 \mathrm{~m}^{-1}$ ( 真光层深度 $0.26 \mathrm{~m}$ ), 严重影 响了沉水植物的生长, 故对夏季滆湖水体光学性质进行单独分析,得到夏季 7 月滆湖水体 $K_{\mathrm{d}}$ 与 Chl. a 单因 素分析,结果为:

$$
K_{\mathrm{d}}=0.002 C_{\text {Chl. a }}+3.651\left(R^{2}=0.023, N=15, P=0.592\right)
$$

同时对夏季 7 月滆湖 15 个采样点的 SS 与 $K_{\mathrm{d}}$ 之间的关系进行拟合:

$$
K_{\mathrm{d}}=0.021 \mathrm{SS}+2.754\left(R^{2}=0.497, N=15, P<0.01\right)
$$

可以看出, 夏季 7 月滆湖水体 $K_{\mathrm{d}}$ 与 Chl. a 之间的相关性不显著, 而 $K_{\mathrm{d}}$ 与 SS 之间的相关性明显较 Chl. a 与 $K_{\mathrm{d}}$ 的显著,说明 $\mathrm{SS}$ 是影响滆湖夏季 $K_{\mathrm{d}}$ 变化的主要因子.

2009 年 11 月至 2010 年 1 月秋、冬季节,全湖 $K_{\mathrm{d}}$ 与 Chl. a 之间的线性关系显著提高, 结果为:

$$
K_{\text {d }}=0.051 C_{\text {Chl. a }}+1.659\left(R^{2}=0.585, N=45, P<0.001\right)
$$

这说明滆湖水体中 Chl. a 浓度也是影响 $K_{\mathrm{d}}$ 的重要因子之一, 只是对于夏季滆湖水体而言, 水体中 Chl. a 浓度与 $K_{\mathrm{d}}$ 之间的相关性不显著而已. 但在夏季, 滆湖水体中的营养盐可以刺激固氮藻类的生长,而不同藻类 含有的色素不同,其对光的吸收能力也不同 ${ }^{[27]}$. 在湖泊水体中, 夏季藻类常常聚集成团, 大部分漂浮在水体 表面 ${ }^{[28]}$, 藻细胞内的色素强烈吸收光, 使沉水植物难以得到生长所需要的光. 且藻类死亡降解可以释放出大 量的 $\mathrm{CDOM}^{[29]}$ 、有机悬浮物 ${ }^{[8]}$ 、营养盐及化感物质 ${ }^{[30]}$, 其中 CDOM 可以吸收光谱中的短波部分; 有机悬浮物 对光具有吸收作用,造成光能的损失;营养盐的释放可以促进藻类的下一次暴发. 几种因素的耦合进一步造 成水体 PAR 的衰减,使夏季全湖 $K_{\mathrm{d}}$ 呈现出与其他季节完全不同的情况. 而藻类死亡释放出来的化感物质亦 会抑制沉水植物的生长 ${ }^{[30]}$. 但对于整治后的滆湖水体 $K_{\mathrm{d}}$ 与 Chl. a 浓度之间的关系是否会有所改变,还有待 进一步研究.

\section{3 结论}

通过对 2009-2010 年周年滆湖水体水质参数和 PAR 数据进行分析, 以期能够为评价综合整治后滆湖 水体光学性状及为滆湖进行沉水植物修复提供一定的相关基础资料. (1) 滆湖水体 PAR 衰减系数呈现出显 著的时空差异,在 2009 年 7 月至 2010 年 6 月全湖周年 $K_{\mathrm{d}}$ 变化范围为 $1.32 \sim 17.42 \mathrm{~m}^{-1}$, 夏季 $K_{\mathrm{d}}$ 相对最大, 秋季 $K_{\mathrm{d}}$ 分布相对稳定,4 个季节全湖 $K_{\mathrm{d}}$ 平均值大小依次为:夏季 > 春季 > 冬季 > 秋季. (2) 与春、秋、冬季不 同, 夏季滆湖水体大部分的真光层深度小于滆湖水体的平均深度, 表明 PAR 是夏季滆湖沉水植物生长的限 制因子之一. (3) 滆湖水体的 2 个重要光学性质参数 $K_{\mathrm{d}}$ 与 SD 在秋、冬季的关系为: $K_{\mathrm{d}}=2.089+$ $0.705 / \mathrm{SD}$

致谢: 在数据采集及作图过程中得到黄峰、陶花、宋媛媛的帮助,初稿得到尚丽霞和吴晓东等的相关修改意 见,在此致以诚挚的感谢. 


\section{4 参考文献}

[ 1 ] Karlsson J, Byström P, Ask J et al. Light limitation of nutrient-poor lake ecosystems. Nature, 2009, 460:506-509.

[2] 黄昌春,李云梅,孙德勇等. 秋季太湖水下光场结构及其对水生态系统的影响. 湖泊科学, 2009,21 (3):420-428.

[3] 王 华, 逢 勇, 刘申宝等. 沉水植物生长影响因子研究进展. 生态学报,2008,28(8):3958-3968.

[ 4 ] Karl EH. Submerged aquatic vegetation correlation with depth and light attenuating materials in a shallow subtropical lake. Hydrobiologia , 2003, 493(1/2/3): 173-186.

[ 5 ] Zhang M, Cao T, Ni LY et al. Light-dependent phosphate uptake of a submersed macrophyte Myriophyllum spicatum L. Aquatic Botany, 2011, 94(4): 151-157.

[6] 朱宜平,张海平. 小型富营养水体光合有效辐射衰减特性分析. 环境污染与防治,2011,33(3):65-68.

[ 7 ] 张运林, 秦伯强,陈伟民等. 太湖水体光衰减系数的分布及其变化特征. 水科学进展, 2003,14(4):447-453.

[ 8 ] 余雪芳,胡江琴, 毛成责等. 杭州西湖冬、春季水体光学特性比较. 环境科学研究,2008,21(4):119-125.

[9] 邹丽莎, 聂泽宇, 姚笑颜等. 富营养化水体中光照对沉水植物的影响研究进展. 应用生态学报, 2013,24 (7): 2073-2080.

[10］范成新. 滆湖沉积物理化特征及磷释放模拟. 湖泊科学, 1995,7(4) :341-350.

[11] 陶 花,潘继征,沈耀良等. 滆湖沉水植物概况及退化原因分析. 环境科技,2010,23(5):64-68.

［12］盛建明,曹文明,刘玨琴等. 滆湖富营养化变动趋势及防治对策研究. 见: 朱成德, 王玉纲,余 宁编. 滆湖渔业高产 模式及生态渔业研究论文集. 北京: 中国农业出版社,1995:48-52.

［13］盛建明,刘坧琴, 曹文明等. 滆湖水质变化趋势和富营养化评价. 见: 朱成德, 王玉纲,余 宁编. 滆湖渔业高产模式 及生态渔业研究论文集. 北京: 中国农业出版社,1995:40-47.

[14] 彭自然,陈立婧,江 敏等. 滆湖水质调查与富营养状态评.上海水产大学学报,2007,16(3):252-258.

[15] 国家环境保护总局《水和废水监测分析方法》编委会. 水和废水监测分析方法: 第 4 版. 北京: 中国环境科学出版 社,2002:100-672.

[16] 卡尔夫著.古滨河,刘正文,李宽意等译. 湖沼学: 内陆水生态系统. 北京:高等教育出版社,2011:135-152.

[17] 徐耀阳, 叶 麟, 韩新芹等. 香溪河库湾春季水华期间水体光学特征及相关分析. 水生生物学报, 2006, 30 (1): 84-88.

[18］黄 峰. 滆湖沉水植物群落重建及水质净化效果研究 [学位论文]. 苏州: 苏州科技学院,2011.

[19] Schindler DW, Hecky RE, Findlay DL et al. Eutrophication of lakes cannot be controlled by reducing nitrogen input: results of a 37-year whole-ecosystem experiment. Proceedings of the National Academy of Sciences of the United States of America, $2008, \mathbf{1 0 5}(32)$ : 11254-11258.

[20] Havens KE, James RT, East TL et al. N:P ratios, light limitation, and cyanobacterial dominance in a subtropical lake impacted by non-point source nutrient pollution. Environmental Pollution, 2003, 122(3) : 379-390.

[21] Xie L, Xie P, Li S et al. The low TN:TP ratio, a cause or a result of Microcystis blooms? Water Research, 2003, 37(9) : 2073-2080.

[22] Kenworthy WJ, Fonseca MS. Light requirements of seagrasses Halodule wrightii and Syringodium filiforme from the relationship between diffuse light attenuation and maximum depth distribution. Estuaries, 1996, 19(3) : 740-750.

[23] 童昌华, 杨肖娥, 誉培民. 水生植物控制湖泊底泥营养盐释放的效果与机理. 农业环境科学学报, 2003,22(6): 673-676.

[24] 洪 喻,胡洪营. 水生植物化感抑藻作用研究与应用. 科学通报,2009,54(3):287-293.

[25] 张运林, 秦伯强, 陈伟民等. 不同风浪条件下太湖梅梁湾光合有效辐射的衰减. 应用生态学报, 2005, 16 (6): 1133-1137.

[26] Zhang YL, Liu XH, Yin Y et al. Predicting the light attenuation coefficient through secchi disk depth and beam attenuation coefficient in a large, shallow, freshwater lake. Hydrobiologia, 2012, 693(1): 29-37.

[27] 周虹丽,朱建华, 韩 冰等. 几种典型藻种吸收光谱特性的比较. 海洋技术,2010,29(3):78-92.

[28] 罗永刚,朱 伟,李 明等. 群体大小对微襄藻细胞昼夜垂向迁移的影响. 湖泊科学, 2013,25(3):386-391.

[29] Zhang YL, Van DMA, Liu ML et al. The contribution of phytoplankton degradation to chromophoric dissolved organic matter (CDOM) in eutrophic shallow lakes: Field and experimental evidence. Water Research, 2009, 43 (18) : 4685-4697.

[30］刘丽贞,秦伯强,朱广伟等. 太湖蓝藻死亡腐烂产物对狐尾藻和水质的影响. 生态学报,2012,32(10):3154-3159. 